\title{
Prazer e virtude segundo Aristóteles
}

\author{
Juliana Ortegosa Aggio \\ juaggio@yahoo.com.br \\ Universidade Federal da Bahia (UFBA), Salvador, Brasil
}

resumo 0 presente texto pretende examinar a relação estabelecida por Aristóteles entre prazer e virtude de modo a compreender a seguinte tese aristotélica: o virtuoso não age devido ao prazer, mas necessariamente com prazer. Esta tese será mais bem compreendida com a exposição que faremos da concepção aristotélica de prazer, tal qual elaborada pelo filósofo no segundo tratado do prazer de sua Ética Nicomaqueia. Como veremos, a definição do prazer como um fenômeno cuja existência e natureza dependem inteiramente da existência e natureza da atividade a qual pertence nos permite inferir que o juízo de valor que incide sobre a atividade é o critério de valoração moral do prazer, e não o contrário. Isso significa que o virtuoso julga qual seria a melhor atividade a ser realizada e não qual atividade the dará prazer. Com efeito, veremos que o virtuoso deseja realizar certa atividade por ela ser boa e não por ela ser prazerosa, ou seja, embora o prazer não seja a razão da ação, ele será a sua consequência inevitável.

palavras-chave Prazer; desejo; virtude; razão; Ética Nicomaqueia; Aristóteles

\section{Introdução}

O prazer, segundo Aristóteles, exerce um papel relevante na formação do caráter e na regulação de nossas ações morais, o que é evidente quando filósofo afirma que "a virtude moral diz respeito aos prazeres e dores" (EN II, 3, 1104b9), e apresenta, em seguida, oito razões como justificativa. Destas, destaco quatro que, a meu ver, são as mais relevantes. Em primeiro lugar, por causa do prazer (dia tênhêdonên) realizamos ações vis e por causa 
da dor nos afastamos das belas ações; o que justifica a importância de se educar desde cedo a criança a gostar (chairen) e desgostar do que se deve. Em segundo lugar, a virtude diz respeito às ações e emoções (pathê), e toda ação e emoção são acompanhadas de prazer $^{1}$; o que pressupõe que, como acompanhante, ele terá algum efeito sobre nossas ações e, portanto, na aquisição das disposições morais. Em terceiro lugar, a relação da disposição moral com o prazer e a dor parece ser necessária e de absoluta relevância moral, o que torna a investigação sobre tal relação crucial, pois "pelos prazeres e dores os homens tornam-se vis, ao buscar e evitar aqueles que não se devem, ou quando não se devem, ou como não se devem ou de tantos outros modos nos quais se possa definir" (1104b21-24) $)^{2}$, e, inversamente, tornam-se bons, a depender de quais, como e quando buscam os prazeres e evitam as dores. Isso se explica pela natureza mesma de toda disposição moral, pois que esta é determinada pelas coisas que tornam a alma melhor ou pior com relação a elas, i.e., aos prazeres e dores. Em suma: o tipo de comportamento com relação aos prazeres e dores é determinante na constituição da disposição moral. Donde conclui Aristóteles o que se segue: "assumimos, portanto, que a virtude é de tal qualidade conforme o bem agir em relação aos prazeres e dores, e que o vício é o contrário" (1104b26-7). Por fim, em quarto lugar, Aristóteles nos diz que o prazer acompanha todo objeto de busca, seja ele um objeto propriamente prazeroso, seja ele o belo e o útil, a saber:

"Como são três os objetos de busca e três os de fuga - o belo, o proveitoso e o agradável - e três contrários - o feio, o danoso e o penoso -, o homem bom é correto a respeito de todos eles, mas sobretudo a respeito do prazer, pois este é comum aos animais e acompanha a tudo o que cai na rubrica busca (aïproıv) ${ }^{3}$, pois o belo e o proveitoso nos parecem ser prazerosos" (1104b30-1105a1).

Ora, se o prazer acompanha todo objeto de busca, i.e., todo objeto de desejo que seja realizável ${ }^{4}$, se o modo de se comportar com relação aos prazeres e dores é tão importante para a formação do caráter e, evidentemente, para regularmos nossas ações ${ }^{5}$, então, parece ser evidente que o filósofo tenha atribuído ao prazer um papel determinante na conduta moral. O ponto problemático, que norteará esta investigação, é saber o quão determinante ele é. Não poderia ser, ele próprio, o critério para 
determinar o valor moral da ação, pois se o fosse, a boa ação seria identificada com o ter prazer e a má ação com o ter dor; contrariando o que pretende estabelecer Aristóteles.

Explico-me. Se o prazer é determinante para a aquisição da disposição moral, pois nos tornarmos bons se o buscamos corretamente e vis se assim o fazemos incorretamente, como foi dito, então devemos compreender o tipo de determinação que ele exerce na orientação de nossas ações. Uma hipótese que poderia ser levantada se o nosso comportamentofosse absolutamente determinado pela busca de prazer seria a seguinte: se assim fosse, bastaria dizer que a busca correta pelo prazer é tudo o que deve aprender aquele que pretende se tornar virtuoso, e que o fim de suas ações não deve ser o prazer simplesmente, mas o prazer qualificadamente bom.

Diante desta hipótese, duas perguntas devem ser feitas para saber se ela se sustenta ou não. Em primeiro lugar, como é possível ter um prazer qualificadamente bom? Em segundo lugar, é o prazer, mesmo que bom, que deve ser desejado em vista dele mesmo e assim operar como critério último da ação virtuosa? Quanto à primeira pergunta, veremos que a definição de prazer tal qual proposta por Aristóteles, no segundo tratado do prazer (EN X 1-5), condicionará o bom prazer à realização da boa atividade, o que significa dizer que só é possível ter um bom prazer ao se realizar uma boa atividade. Quanto à segunda pergunta, veremos que o prazer não poderia operar como critério da ação virtuosa porque é possível ter prazer com ações vis - ora, se o prazer fosse critério, então qualquer ação que desse prazer, seja ela boa ou vil, deveria ser realizada - o que implica constatar que a ação deve ser objeto de desejo e não o prazer. Ou seja, o prazer não poderia ser objeto de desejo do virtuoso, embora seja sua consequência inevitável.

Com efeito, bem sabemos que, segundo o estagirita, o bem e não o prazer deve ser o fim último de nossas ações. Que o fim último, a felicidade (eudaimonia), é o bem a ser desejado em vista de si mesmo, e não o prazer, Aristóteles já nos demonstrou desde os primeiros capítulos de sua Ética Nicomaqueia. Contudo, o prazer, mesmo não sendo causa suficiente, certamente será causa necessária para a realização da felicidade. Isso significa dizer que o prazer é determinante, por ser necessário, mas não suficiente, para a realização da felicidade. Do contrário, bastaria ter prazer para ser feliz, o que não é o caso ${ }^{6}$. Se a felicidade não pode ser identificada 
com o prazer, tampouco ele poderia ser excluído de seus elementos constituintes. Afinal, uma vida em função do prazer é antes escrava do prazer e se aproxima de uma vida bestial do que propriamente humana ${ }^{7}$; todavia, como diz a maioria, a felicidade existe "com prazer" (meth'hêdonês) ${ }^{8}$. Compreender, portanto, em que sentido o prazer é necessário para a felicidade pressupõe compreender a relação necessária entre virtude e prazer, visto que a virtude é a causa principal da felicidade.

O prazer, como veremos, não pode ser nem o bem absoluto, nem o mal absoluto, embora possa ser um bem se estiver acompanhando uma boa atividade. Ora, se bastasse ao virtuoso desejar o que lhe dá prazer e assim agir conformemente, então o prazer teria de ser considerado o bem em absoluto, e Aristóteles teria de ser partidário de um hedonismo radical, como foi Eudoxo. Se, por outro lado, o virtuoso não sentisse qualquer prazer ao agir, então o prazer teria de ser considerado o mal em absoluto, como postulou Espeusipo. Seria deveras absurdo, ou sem sentido, se Aristóteles defendesse uma concepção anti-hedonista diante da importância que ele mesmo confere ao prazer em sua ética.

Podemos dizer, sem ressalvas, que o hedonismo moderado sustentado por Aristóteles se apresenta claramente no tipo de relação que ele estabelece entre virtude e prazer, a saber: o virtuoso não age tendo em vista o prazer por ele mesmo, mas certamente sente prazer ao agir. Com a exposição da definição de prazer do segundo tratado do prazer, e da tese da diferença específica entre os prazeres, pretendo tornar patente que a definição do prazer como um fenômeno que não existe senão enquanto um acompanhante da atividade aduz à tese de que o prazer não poderia ser o critério para a ação virtuosa. Isso porque o prazer não é o objeto sobre o qual incide o julgamento do virtuoso, visto que ele não existe por ele mesmo ou em si mesmo, ou seja, a sua existência e natureza dependem inteiramente da existência e da natureza da atividade a ser realizada.

Ainda assim, partidários de um hedonismo radical, poderíamos dizer que a atividade percebida como prazerosa deveria ser escolhida em detrimento da atividade apreendida como virtuosa. Todavia, se ser prazerosa fosse o critério para se escolher determinada atividade a ser realizada, como as atividades vis também são prazerosas, logo, qualquer atividade, independentemente de seu valor moral, poderia ser escolhida. Para que o 
prazer, i.e., a atividade prazerosa não ocupe o lugar da atividade virtuosa na escolha correta, Aristóteles postula que o bom julgamento deverá incidir sobre a atividade por ela ser boa e não por ela ser prazerosa, ou seja, o julgamento correto buscará apreender o valor moral da atividade e não o seu aspecto prazeroso. Com efeito, o virtuoso será aquele que julga qual a melhor atividade a ser feita e não qual o prazer a ser fruído em dada situação. Isso significa que tal atividade não será boa por parecer prazerosa ao virtuoso, mas, ao contrário, ela lhe parecerá prazerosa por ser boa. $\mathrm{O}$ virtuoso não age corretamente para ter prazer, ou seja, não é o prazer a causa de sua ação, mas é por agir assim que ele tem prazer, ou seja, é por ser boa que sua ação lhe causa prazer - e não ao contrário: por ser prazerosa que ela é boa. Em outros termos, a causa do prazer do virtuoso é a realização da boa ação e a causa da realização da boa ação é ela mesma. $\mathrm{Ou}$ seja, a ação virtuosa não é a realização de uma atividade por ela ser prazerosa, mas por ela ser boa, embora a sua realização seja necessariamente prazerosa ao virtuoso.

Tendo em mente tais considerações, pretendo, com este texto, mostrar que a concepção de prazer que Aristóteles apresenta, no segundo tratado, expressa sua visão hedonista moderada e corrobora com a tese de que o virtuoso age não devido ao prazer, mas certamente com prazer.

\section{0 hedonismo moderado de Aristóteles}

Não parece ser de pouca monta o fato de o filósofo ter defendido uma tese hedonista moderada, em que o prazer, embora não seja o bem, possa ser um bem, uma vez que esteja acompanhando uma boa atividade. Como vimos, o prazer não poderia ser o bem supremo, pois ele é causa necessária, mas não suficiente da felicidade 9 . Por outro lado, se o prazer fosse o mal em absoluto, ele não poderia ser considerado uma das causas da felicidade e jamais poderíamos ter prazer com o que é bom. Em seus dois tratados do prazer ${ }^{10}$, Aristóteles critica as opiniões anteriores sobre o prazer de modo a defender a tese de que o prazer não é o bem ou o mal em absoluto, mas que, cumpridas certas exigências, ele possa ser considerado um bem. Veremos, mais adiante, quais são estas exigências a serem cumpridas para que o prazer possa ser um bem. 
Depois de ter definido o objeto de sua ética, a felicidade (eudaimonia), Aristóteles, no livro I, capítulo 8 (1098b9-1099b8), passa a verificar a validade de tal definição à luz das opiniões correntes. Ele nos diz que são três as opiniões que estão em harmonia com a sua definição de felicidade. A primeira delas é aquela que diz que o fim se identifica com as ações ou atividades, pois estas são bens da alma. A segunda diz que o homem feliz vive e age bem, pois a felicidade é um tipo de viver e agir bem. Por fim, a terceira opinião é a de que a felicidade inclui, de alguma maneira, todas as características que lhe foram atribuídas, a saber: a virtude, a prudência, a sabedoria, o prazer e os bens exteriores. Além de a felicidade envolver os bens supracitados e de ser o exercício da virtude e não apenas a sua posse, o filósofo acrescenta, em seguida, que a vida daqueles que são felizes é em si mesma prazerosa, pois a vida virtuosa é em si mesma prazerosa. Ao justificar tal afirmação, o estagirita demonstra que a felicidade necessariamente envolve prazer e este ponto nos interessa sobremaneira.Vejamos o trecho referido:

"Com efeito, a vida deles <i.e., dos virtuosos $>$ é em si mesma prazerosa

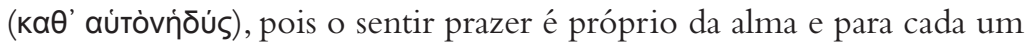
lhe é prazeroso aquilo que ele ama. Por exemplo, o cavalo é prazeroso para aquele que ama cavalos; o espetáculo para aquele que ama assistir espetáculos; e, similarmente, as ações justas são prazerosas para os que amam a justiça e, em geral, as ações virtuosas para os que amam a virtude. Assim, para a maioria, os prazeres estão em conflito um com o outro, porque eles não são por natureza prazerosos; enquanto que as coisas prazerosas por natureza são prazerosas para os que amam o belo e estas são sempre ações conforme a virtude, de tal modo que são prazerosas em si mesmas e para os que amam o belo ${ }^{11}$. A vida deles, portanto, não necessita do prazer como uma espécie de ornamento (пгріо́ттоu), mas tem prazer em si mesma. Além do que já dissemos, o homem, portanto, que não frui das belas ações não é nada bom. Tampouco se chamaria justo aquele que não frui de ações justas; nem generoso aquele que não frui de ações generosas e similarmente com as outras virtudes. Em sendo assim, ações em conformidade com a virtude devem ser em si mesmas prazerosas. Mas também são maximamente

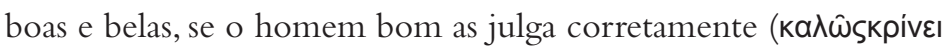

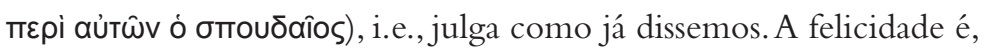


portanto, o que há de melhor, mais belo e prazeroso e essas qualidades não estão separadas como estão no epigrama de Delfos - o mais belo é a justiça/ e o melhor é a saúde; / mas o mais prazeroso é conquistar o que amamos -, pois todas essas qualidades pertencem às melhores atividades. E essas ou uma dessas é a melhor de todas - aquela que dizemos ser a felicidade" (1099a7-30).

No trecho acima, o estagirita mostra que a felicidade, i.e., a vida dos virtuosos, é em si mesma prazerosa e que, portanto, não seria possível admitir que o prazer seja mero ornamento a ser acrescido ou retirado facilmente deste tipo de vida. Esta tese, como veremos, implica três coisas: (i) a ação virtuosa é por natureza prazerosa e o virtuoso necessariamente sente prazer ao realizá-la, sendo o prazer que ele sente um sinal de sua disposição virtuosa (1099a17-21); (ii) além de ser prazerosa, tal ação é boa e bela em mais alto grau, ou seja, o prazer, assim como o bem e a beleza, é um atributo próprio da ação virtuosa (1099a22-25), e, (iii) que a inscrição de Delfos é falsa, pois a reunião de excelência, beleza e prazer se expressa em uma única atividade, a saber: a felicidade (1099a25-31). Comecemos pela crítica à inscrição de Delfos.

Segundo tal inscrição, o belo, o melhor e prazeroso aparecem separados, ao contrário do que compreende Aristóteles, pois, para o mesmo, a felicidade é a melhor e mais bela atividade, portanto, a mais amada e desejada dentre todas as atividades. Se a realização do que amamos ou desejamos proporciona prazer, então a realização daquilo que mais amamos, a felicidade, certamente proporcionará o máximo de prazer. Isso significa que a crítica à inscrição de Delfos parece ter o intuito de mostrar que o prazer é um atributo próprio à felicidade, i.e., o prazer necessariamente ocorre ao realizarmos o bem viver. É exatamente esta concepção de felicidade como atividade necessariamente prazerosa que nos interessa.

No início do trecho citado acima, o filósofo postula que a vida dos virtuosos é em si mesma prazerosa, pois as ações conforme a virtude são prazerosas em si mesmas e para os que amam a virtude. Ou seja, o que é realmente prazeroso assim o é em si mesmo e para quem o sente, assim como o que é bom assim o é em si mesmo e para quem ama o que é bom, i.e., para aquele que possui uma boa disposição. Isso se explica pelo fato de existir, segundo o filósofo, tanto o bem em si (haplôs), como o bem 
para mim (hautôi) ou fenomênico. Do mesmo modo, há tanto prazer haplôs, como prazer hautôi ${ }^{12}$. Com efeito, "o que é bom por natureza é o que é bom e prazeroso ao homem bom e em si mesmo" (EN IX,9, 1170a15) ${ }^{13}$. Ainda, como analisaremos adiante, nesta outra passagem, o estagirita expõe esta mesma concepção: "em todos esses casos, o que parece ser é o

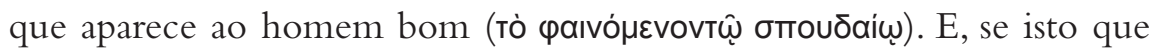
falamos está correto como parece estar, a virtude e o homem bom qua bom são a medida (нદ́трov) de cada coisa. Portanto, as coisas que lhe aparecerem prazerosas são prazerosas e agradável é aquilo com o qual ele se deleita" (EN X, 5, 1176a16-19).

Quanto ao que fora dito é preciso ressaltar que não é o que é bom para o virtuoso que é bom em si mesmo, mas exatamente o contrário: o que é bom em si mesmo assim parece ser bom para o virtuoso justamente porque ele é capaz de julgar corretamente o que a situação particular determina como sendo o melhor a ser feito ${ }^{14}$. Ora, sabemos que o realismo aristotélico não é complacente com a máxima de Protágoras de que "o homem é a medida de todas as coisas", pois, para ele, a medida do que é bom é dada pelas circunstâncias particulares presentes na realidade e o virtuoso é justamente aquele que é capaz de apreender verdadeiramente o que é realmente bom. Por isso, assim como o bem existe tanto em si mesmo como para quem o toma como tal, a ação virtuosa é tanto em si mesma prazerosa como para quem a toma como prazerosa, ou seja, para quem ama agir virtuosamente. Mas não é por apreendê-la que ela se torna prazerosa por natureza, ao contrário, é porque ela é prazerosa por natureza que o virtuoso pode apreendê-la enquanto tal. Em suma: ela não é prazerosa em si mesma por assim parecer ser ao virtuoso. Ao contrário, ela é prazerosa para o virtuoso por assim ser em si mesma ou por natureza.

Ademais, quem não tem prazer com o que é prazeroso por natureza não pode ser considerado virtuoso por excelência. Afinal, "o homem que



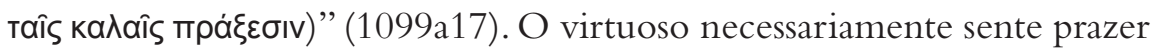
ao agir virtuosamente e o prazer que ele sente é um sinal de que ele é, de fato, virtuoso. Além do temperante, que se caracteriza justamente por ser moderado quanto aos prazeres físicos, sobretudo os do tato e paladar, outros dois exemplos claramente confirmam esta tese de que o virtuoso necessariamente sente prazer ao agir virtuosamente: o do generoso e o do 
corajoso. $\mathrm{O}$ generoso sente prazer em dar com vistas ao belo e corretamente; como diz o filósofo: "ele dará com prazer ou sem dor, pois a ação segundo a virtude é prazerosa ou sem dor - certamente não é penosa" (EN IV 1: 1120a26-7).

Mais exemplar ainda é o caso do corajoso, cuja ação corajosa lhe é prazerosa mesmo que seja acompanhada de dores físicas. Aquele que é propriamente corajoso faz o que é bom em vista do que é bom e sente prazer com isso. Os corajosos por homonímia recebem apenas o nome de corajosos, pois não são realmente corajosos, ou seja, eles não agem em vista do próprio bem, da própria ação corajosa, mas sim em vista do prazer da honra, ou do elogio posterior, ou ao menos para não serem desonrados ou punidos ${ }^{15}$. Segundo Aristóteles, "alguém deve ser corajoso não por coerção, mas porque é belo ser assim” (EN III 9: 1116b3) ${ }^{16}$. Ora, a ação corajosa é prazerosa para quem é verdadeiramente corajoso, ainda que seja preciso enfrentar certas dores, como as dores fisicas na batalha e mesmo a pior das dores: a própria morte ou a morte de alguém querido. O caso do corajoso parece funcionar bem como um paradigma para determinar que o prazer seja, sobretudo, uma sensação da alma $(1099 \mathrm{a} 9)^{17}$, pois mesmo sentindo dor física, o corajoso sente prazer ao agir corajosamente, i.e., ao ser virtuoso e desejar o bem em vista dele mesmo. Tendo como alvo o próprio bem, o corajoso não se desvia de seu alvo por não suportar a dor física, ou por buscar o prazer acima do que é bom. O mesmo, obviamente, deve se seguir com relação às outras virtudes.

Tendo em vista o que foi dito, podemos inferir que o virtuoso necessariamente sente prazer ao agir porque a ação virtuosa lhe aparece como sendo prazerosa mesmo que ela implique dor. Em poucas palavras: o virtuoso só suporta as dores que deve suportar ou evita os prazeres que deve evitar porque tem em mira e se regozija com o que é belo e bom. Como diz Alexandre de Afrodisia, "nós escolhemos atividades virtuosas mesmo que elas possam, às vezes, nos causar sofrimento ou dor, como ocorre no caso das atividades corajosas" (Problema 13: 144, 11-14).

Como argumento suplementar, Aristóteles postula a tese de que o prazer que sente o agente é um sinal ou indício (sêmeion) ${ }^{18}$ de que a ação virtuosa é realizada por alguém virtuoso. Isto se explica por duas razões. Em primeiro lugar, sabemos que toda ação é acompanhada de prazer ou dor, e que o virtuoso não age tendo o prazer como fim, mas certamente 
sua ação é acompanhada de prazer $^{19}$. Em segundo lugar, dizer que temos prazer ou dor ao agir desse modo ou de outro sinaliza o nosso tipo de caráter, pois evidencia o tipo de desejo que está operando: se for um desejo virtuoso, então a realização do bem em vista dele mesmo proporcionará um bom prazer; se não for, então ou o objeto de desejo será algo vil, como no caso do vicioso, ou não será o próprio bem, mas sim sua consequência prazerosa ou não penosa, como parece ocorrer nos casos de controle (encrateia) ou de descontrole (acrasia) ${ }^{20}$. Logo, haverá ou um prazer ruim, i.e., aquele que acompanha a ação vil, ou um prazer pela consequência da ação boa, e não pela própria ação ${ }^{21}$. Nas palavras de Aristóteles:

"deve-se tomar os prazeres e as dores nas ações como sendo sinais

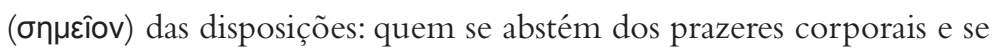
deleita (xaipwv) com isso é temperante; ao passo que quem se incomoda com isso é intemperante; quem suporta as coisas temíveis e se deleita, ou ao menos não sofre, é corajoso; ao passo que quem sofre é covarde" (EN II $3: 1104 b 3-8)$.

Se, pois, o prazer e a dor indicam que tipo de disposição possui aquele que pratica a ação, então é de se presumir que agir bem implica sentir prazer e dor com o que se deve e como se deve. Mais ainda, se o prazer é sinal da boa ação, então é porque a boa ação foi realizada com prazer.

Quando o filósofo diz que "a virtude é de tal qualidade conforme o bem agir em relação aos prazeres e dores, e que o vício é o contrário" (EN II, 3, 1104b26-7), pois nos tornamos bons ao buscarmos corretamente o prazer e maus ao buscá-lo incorretamente, não devemos compreender que ele esteja propondo uma espécie de hedonismo radical, em que o prazer funcionaria como critério da boa ação. Ao contrário, a boa ação é critério para o prazer, pois não se trata de sentir prazer com qualquer coisa que pareça prazerosa, mas com o que é preciso sentir e do modo que é preciso sentir, i.e., moderadamente. Ora, o virtuoso é justamente aquele que sente prazer com o que se deve e na justa medida, e que também sabe enfrentar ou evitar as dores necessárias. Isso porque ao virtuoso lhe é prazeroso o que é verdadeiramente um bem. Com efeito, para o homem bom as boas coisas lhe aparecem como prazerosas e para o homem mau, as más ${ }^{22}$.

Conforme a análise do trecho 1099a7-30, torna-se evidente que tipo de relação existe entre prazer e felicidade e o quão necessário é o prazer 
para vivermos bem. Do que foi dito até o momento, podemos concluir que, desde o início da Ética Nicomaqueia, é preciso que o prazer possa ser considerado um bem, visto que tanto a felicidade, como a virtude são bens e são coisas naturalmente prazerosas. Desse modo, Aristóteles parece ter defendido uma tese hedonista moderada, em que o prazer, embora não seja o bem, possa ser um bem uma vez que esteja acompanhando a realização de uma boa atividade. As condições pelas quais o prazer pode ser um bem serão fornecidas no segundo tratado do prazer, como veremos adiante.

\section{0 prazer não é critério para a ação virtuosa}

A ação virtuosa, como vimos, é em si mesma prazerosa e também é necessariamente prazerosa para o virtuoso, pois ele ama agir virtuosamente. Todavia, mesmo sendo em si mesma prazerosa e necessariamente prazerosa ao virtuoso, a ação virtuosa deve ser desejada e escolhida por ser boa e não por ser prazerosa. Neste momento de nossa investigação, é preciso mostrar por que, segundo Aristóteles, não é por ser prazerosa que a ação virtuosa deve ser desejada, mas por ela ser boa. Como veremos, sustentar esta tese afasta o filósofo de uma possível adesão ao hedonismo exacerbado.

Sabemos que, segundo Aristóteles, a ação virtuosa deve ser desejada em vista dela mesma, i.e., por ser boa e não por resultar em prazer. Isto se justifica a partir de dois argumentos. O primeiro é que devemos desejar e escolher o que é bom a ser feito, tendo como critério o próprio bem e não o prazer, i.e., o julgamento sobre o que é realmente um bem e não o julgamento sobre o que é prazeroso. Mesmo porque, o julgamento sobre o que é prazeroso determina o que é prazeroso, mas não necessariamente o que é bom, já que não há identidade absoluta entre prazer e bem. O segundo argumento consiste em dizer que o erro moral ${ }^{23}$ decorrente dos prazeres consiste em desejarmos fazer algo que seja bom por parecer prazeroso e não por ser de fato bom, pois comumente escolhemos antes o que simplesmente nos parece ser prazeroso do que o que a razão nos diz que é bom. Neste caso, o erro moral ocorre porque o prazer é tomado como critério do que é bom, e não o contrário, o que é bom como critério para se ter prazer. Todavia, se o critério para fundamentar o que é bom 
fosse o que aparece como prazeroso, a ética aristotélica seria absolutamente hedonista e a figura elogiável por excelência não seria a do prudente e sim a do intemperante. Afinal, o intemperante age tendo como fim apenas o que lhe dá prazer, independentemente de seu valor moral ${ }^{24}$.

Certamente, é tese bem estabelecida na ética aristotélica que a ação virtuosa não deva ser desejada em vista do prazer, mas sim em vista de ela mesma ser virtuosa. Porém, como comumente desejamos o que nos aparece como prazeroso e o que nos aparece como prazeroso não nos fornece um critério moral aceitável, então, deve ser possível e necessário que o que nos apareça como prazeroso esteja condicionado ao que julgamos corretamente ser bom. Afinal, também é tese bem estabelecida que o critério moral deva ser o bom julgamento, i.e., aquele mesmo que o prudente faria.

Vejamos, agora, como a definição de prazer proposta no segundo tratado corrobora com a tese de que o virtuoso age devido ao bem e não devido ao prazer, uma vez que o seu julgamento incidirá sobre a atividade e não sobre o prazer.

\section{A definição de prazer}

Pretendemos, agora, mostrar em que sentido a definição do prazer e a tese da diferença específica entre os prazeres corroboram com a tese de que o prazer não poderia servir como o critério para a realização da boa atividade.

Depois de ter fornecido, em ENX 4, os atributos essenciais do prazer, a saber, que ele é um todo completo e indivisível e que a atualização de sua essência é imediatamente completa, Aristóteles chega à definição de prazer, no capítulo seguinte (1174b32-1175a22). Em verdade, a definição não é fornecida de modo claro e contundente, mas por acréscimo de atributos no decorrer do capítulo. Primeiramente, foi dito que ele é um todo completo e indivisível, mas dizer isto apenas garante que a sua natureza não seja processual $^{25}$. Ainda é preciso dizer em que sentido e sob quais critérios podemos efetivamente considerá-lo um bem, pois considerá-lo como um todo completo e indivisível certamente não nos fornece critério algum de valoração moral sobre a natureza do prazer; apenas garante que ele possa ser um bem por não ser um processo. O critério, como veremos, dependerá da natureza da atividade à qual ele pertence. Passemos a definição propriamente dita. 
O prazer é definido como um fim ou perfeição que sobrevém (epigignomenon ti telos) ${ }^{26}$ e retroage sobre a própria atividade (energeia) à qual pertence aperfeiçoando-a. Diante de tal definição, interessa-nos sobretudo entender em que sentido o prazer é próprio ou pertence (oikeia) a uma atividade. Deixemos de lado, para a presente análise, o seu atributo de ser capaz de aperfeiçoar (teleiô̂) a atividade ${ }^{27}$. Brevemente, podemos dizer que oikeia significa "pertencer" ou "ser próprio a". No caso, o prazer que pertence a uma atividade é aquele que vem a ser em virtude da natureza da própria atividade que o agente está atualmente realizando ${ }^{28}$.

Com efeito, o prazer pertence à atividade de modo a não existir nem lógica nem ontologicamente em separado dela, pois não apenas a sua existência, mas também a sua definição dependem da existência e da definição da atividade. Ontologicamente, pois não há prazer sem atividade (1175a21); e, logicamente, pois não está nem no tempo, nem por natureza separado da atividade, ao contrário do desejo, que existe anteriormente à realização da atividade. Ou seja, o prazer é uma atividade que não subsiste por si mesma, mas é absolutamente dependente da atividade perceptiva ou noética a qual pertence ${ }^{29}$.

Por isso, não há definição do valor moral do prazer senão a partir do valor moral atribuído à atividade. E, como as atividades são distintas e variadas, também o serão os prazeres. Nas palavras do filósofo:

"Diferindo as atividades quanto à bondade e à vileza, e sendo umas dignas de serem perseguidas, outras evitadas, e outras ainda neutras, o mesmo se dá também com os prazeres; pois, para cada atividade, há um prazer que lhe é próprio (oikeîaı). O prazer próprio de uma boa

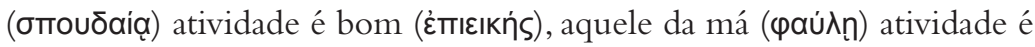

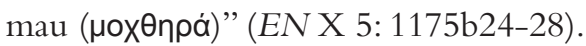

A citação acima estabelece claramente a tese da diferença específica entre os prazeres, que, aos olhos de Alexandre de Afrodisia, nos conduzirá inevitavelmente à seguinte consequência:

"não é dos prazeres produzidos que nós julgamos as atividades que os produzem, ao contrário, nós julgamos os prazeres pelas atividades. As atividades não merecerão ser escolhidas tendo em vista os prazeres, nem serão os prazeres os mesmos em espécie um em relação ao outro" (Problema 13, 134, 13-17). 
Da tese da diferença específica, segue-se que a distinção entre as espécies de prazeres não poderia ser apenas acidental, ou seja, a diferença entre prazeres não é apenas porque acontece de existir certo prazer segundo certa atividade que difere de outro prazer segundo outra atividade, mas porque o prazer que acompanha a atividade lhe é próprio e se diferencia de outro prazer na mesma medida em que uma atividade se diferencia de outra, visto que sua natureza corresponde à da atividade. Isso explica o fato de que as atividades a serem evitadas pelo temperante (i.e., as atividades do intemperante) dificilmente lhe dariam $\operatorname{prazer}^{30}$. Se não fosse assim, como diferenciaríamos os prazeres que acompanham as atividades vergonhosas dos que acompanham as louváveis? São as atividades vergonhosas e louváveis a causa da diferença entre os prazeres, pois, como diz Alexandre de Afrodisia, "as atividades não derivam o seu valor de escolha dos prazeres, mas os prazeres das atividades, já que é até mesmo por causa das atividades que os prazeres são de certo tipo" (Problema 23, 146, 3-5).

A consequência da definição do prazer como um próprio da atividade e como distinto dos outros conforme a atividade a qual pertence é que não há definição do valor moral do prazer senão a partir do valor moral atribuído à atividade. A partir deste argumento, não se poderia mais sustentar a máxima hedonista de que o prazer é o bem em absoluto; nem a máxima anti-hedonista de que ele é o mal em absoluto. Aristóteles parece se mostrar avesso a uma interpretação essencialista do valor moral do prazer. Afinal, com a tese da diferença qualitativa entre os prazeres e a sua definição como sendo absolutamente dependente da atividade à qual acompanha, faz-se evidente que a qualidade moral do prazer depende da qualidade moral da atividade à qual pertence e o valor da atividade, por sua vez, depende do bom julgamento do homem virtuoso. Vejamos, em seguida, como o filósofo estabelece o bom critério para se determinar a boa ação e, consequentemente, o bom prazer.

\section{0 bom critério para a ação virtuosa}

Diante da variedade de espécies de prazeres, Aristóteles estabelece, em EN X 5, que o critério último qualitativo de distinção é o que o homem bom sente, pois, 
"em todos esses casos, o que parece ser é o que aparece ao homem


como parece estar, a virtude e o homem bom qua bom são a medida ( $\mu \dot{\varepsilon} т \rho \circ v)$ de cada coisa. Portanto, as coisas que lhe aparecerem prazerosas são prazerosas e agradável é aquilo com o qual ele se deleita" $(1176 a 16-19)^{31}$.

Como foi dito, a medida de todas as coisas é a virtude e o homem bom qua bom. O seu julgamento moral deve incidir sobre a atividade e não sobre o prazer, pois o prazer não pode ser o critério de valoração da atividade. $\mathrm{O}$ homem bom deseja a boa atividade em vista dela mesma e não em vista do prazer subsequente, o que significa dizer que ela lhe aparece prazerosa, ou seja, que ele encontra o seu prazer na realização da própria atividade e não em sua consequência. A ação virtuosa, por sua vez, é em si mesma boa, mas para que ela seja objeto de desejo de alguém, ela deve aparecer a este alguém como sendo prazerosa. Por isso, a ação virtuosa aparece ao virtuoso como sendo prazerosa por ela ser virtuosa, e não por ela ser prazerosa ou por outra razão qualquer que seja, pois o virtuoso apreende o que é bom e já aprendeu a ter prazer com o que é preciso ter, com o que é de fato bom.

Como sabemos, nem tudo o que é desejado deve ser perseguido e nem tudo o que é objeto de aversão deve ser evitado. É preciso discriminar corretamente o que deve ser perseguido e o que deve ser evitado e, segundo o estagirita, esta discriminação correta é feita pela chamada reta razão (orthos $\log o s)$. Este tipo de operação da razão referente às ações não deve se subordinar ao apetite (epithumia), ao desejo pelo prazeroso, e servir apenas para calcular os meios em vista do fim prazeroso. Uma racionalidade que operasse dessa forma seria apenas instrumental, i.e., serviria apenas para obter os meios mais eficazes para realizar o fim prazeroso, e, como diz o filósofo, já estaria corrompida ${ }^{32}$. Uma racionalidade, por sua vez, moralmente sadia, é aquela capaz de estabelecer corretamente o que deve ser perseguido ou evitado, portanto, de fornecer o bom critério para agir ao apreender o que é verdadeiramente bom ou belo (to kalon). Como diz Alexandre de Afrodisia:

"nos casos em que o belo e o prazer existem juntos, não é o belo que

é para ser escolhido em vista do prazer, mas o prazer [em vista do] que 
é belo, como já mencionamos. Isto é claro pelo fato de que, se o que é belo merecesse ser escolhido em vista do prazer, [o prazer] sendo o fim e merecendo ser escolhido por si próprio, e o belo merecendo ser escolhido [apenas] porque produz prazer, [então] o que é vergonhoso mereceria ser escolhido do mesmo modo que o que é belo, já que [o que é vergonhoso] também produz prazer" (Problema 23: 144, 33-145, 4).

Não é dificil constatar que, se o prazer fosse o critério, então qualquer coisa que produzisse prazer deveria ser escolhida, mesmo que fosse algo vil. Por isso, como foi dito, não é a sensação de prazer ou o desejo pelo prazeroso que poderia distinguir o bom do vil, mas apenas uma discriminação racional que seja capaz de atribuir corretamente um juízo de valor à ação.

Em linhas gerais, sabemos que, a razão (logos), segundo o estagirita, é uma capacidade de distinguir $\operatorname{contrários}^{33}$ e assim apreender o que é verdadeiro e falso, o que é correto e incorreto, enfim, o que é bom e ruim. Já o desejo (orexis) é a capacidade de nos mover na medida em que ele é um movimento (kinesis) ou atividade (energeia) de nossa alma que se realiza no corpo em direção ao que lhe falta, ao objeto desejado ${ }^{34}$. Mesmo sendo um movimento da parte não racional (alogon) da alma, ele pode ser orientado pela razão, i.e., ele pode seguir o que a razão discrimina como sendo bom ${ }^{35}$.

O desejo, por ele mesmo, não é capaz de saber se o objeto desejado é bom ou ruim, se nos leva para uma ação viciosa ou virtuosa, ou mesmo para aquela que está fora do campo da moral: a ação bestial. A avaliação do que é bom ou ruim, do que deve ser desejado ou não, só pode ser feita pela razão. Ora, é por ter em mira o bem que o temperante orienta seus desejos corretamente sobre o que se deve, como e quando se deve ter apetite. Sendo assim, apenas por meio da reta razão podemos ter bons desejos. Eis o modelo do temperante:

"O temperante ( $\sigma \dot{\omega} \varphi \rho \omega v)$ possui o meio termo ( $\mu \dot{\varepsilon} \sigma \omega \varsigma)$ quanto a essas coisas <i.e., os prazeres do tato e do paladar>. Ele não sente prazer com o que mais sente o intemperante, mas antes o desgosta; nem em geral com o que não deve, nem em nada excessivo. Quando lhe faltam, ele não sente dor ou apetite por eles, ou sente moderadamente, não mais do que se deve, nem quando não se deve, nem em geral nada disso. Com efeito, ele deseja prazeres que conduzam à saúde e ao bem-estar de 
modo moderado e como se deve; e deseja outros prazeres, uma vez que estes não impeçam a saúde e o bem-estar e que não sejam contrários ao belo (пара̀тòка入̀̀v), nem excedam seus recursos para obtê-los. Aquele, pois, que negligencia essas coisas, estima mais tais prazeres do que eles mereçam; mas não o temperante que o faz segundo a reta razão

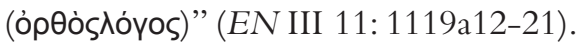

Como vemos, no caso do temperante, a parte apetitiva está em harmonia (symphôneîn) com a razão, pois o temperante é aquele que persegue os prazeres devidos e assim o faz segundo a reta razão. Conduzido pela razão, ele não deseja os prazeres acima do que se deve. Assim, tendo como modelo o temperante, podemos concluir que o desejo, sobretudo o apetite, deve ser conforme a razão, seja por obediência, seja por estar em harmonia com ela. Quando a parte não racional (alogon) obedece à racional - e assim deve ser, pois a parte racional direciona corretamente e conduz para as melhores coisas $^{36}$-, os fins desejados são verdadeiramente bons fins. Com efeito, o filósofo continua mais adiante:

"Os apetites devem ser moderados e poucos, e nunca oporem-

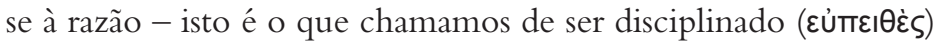

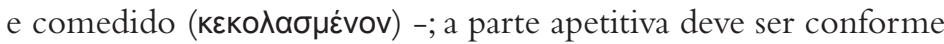

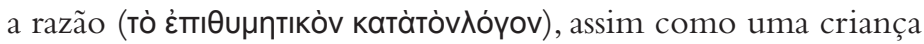
deve viver em obediência ao seu tutor. Por isso, é preciso que a parte apetitiva do temperante esteja em harmonia com a razão (Tò

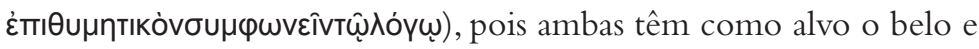
o temperante é aquele que tem apetite com o que se deve, como e quando se deve, assim como ordena a razão” (EN III 12: 1119b11-18).

O adjetivo 'ser disciplinado'(eupeithes) da citação acima, ou seja, ser bem (eu) persuadido ou convencido (peithes) também pode significar ser convicto ou obediente. Portanto, a parte não racional, no caso do temperante, é bem obediente ou é facilmente persuadida pela racional. O adjetivo 'ser comedido' (kekolasmenon) é um particípio derivado do verbo koladzo, que significa mutilar, podar, limitar, punir, reprimir, restringir, controlar; enfim, uma pessoa que já foi limitada é aquela que possui limites quanto aos seus apetites, portanto, é comedida. A parte não racional, i.e., o desejo (orexis) deve ser, segundo o projeto aristotélico de educação moral, obediente e 
limitado ou controlado pela parte racional. A parte racional, por sua vez, deve persuadir e limitar toda e qualquer espécie de desejo, sobretudo o desejo pelo prazeroso, i.e., o apetite (epithumia).

Isso significa que uma pessoa que já seja virtuosa sabe o que é verdadeiramente bom e é facilmente persuadida a desejar e a achar prazeroso o que sua reta razão apreendeu como sendo bom. Por isso, o que o virtuoso julgar como sendo bom necessariamente lhe aparecerá como sendo prazeroso e também será objeto de seu desejo. O virtuoso, cujo desejo obedece à reta razão, terá bons prazeres ou prazeres naturais, enquanto o vicioso, cujo desejo não obedece senão ao seu próprio ímpeto de perseguir o prazeroso, terá maus prazeres ou prazeres antinaturais. Mas, afinal, o que o estagirita pretende dizer com esta classificação de prazer bom e natural e prazer ruim e antinatural ${ }^{37}$ ?

\section{0 bom prazer}

Para compreendermos melhor o tipo de prazer que sente o virtuoso, não basta dizer que ele é moderado e que está em harmonia com a razão; temos, pois, que esclarecer o que Aristóteles denomina por prazer natural ou conforme a natureza. Não é de pouca valia recorrer mais uma vez a Alexandre de Afrodisia que, ao analisar a problemática do prazer na Ética Nicomaqueia, distingue com precisão o prazer antinatural do natural, a saber: o prazer natural é aquele que é próprio de atividades em conformidade com a natureza de cada ser vivo; portanto, segundo Alexandre, o bom prazer se identifica com o prazer natural. O prazer antinatural é prazer por homonímia e é próprio de atividades contrárias à natureza.

Bons prazeres são prazeres naturais desejados moderadamente. Ainda assim, persiste a indagação: como determinar os prazeres que são conformes à natureza? Sabemos que os que estão mais de acordo com a natureza humana, os que mais realizam a função própria (ergon) do homem - a racionalidade - são aqueles próprios do homem bom. Mais uma vez chegamos ao mesmo ponto na ética aristotélica - não apenas para determinação do que é bom, mas também do que é prazeroso - o critério último é o que é em si ou em absoluto. Há tanto o prazer em si (haplôs), como o prazer para si $(h a u t o ̂ i)^{38}$, e o que é prazeroso em si mesmo coincide com o que é prazeroso 
para o homem bom. O que não é em si prazeroso, também não o será para o homem bom, ainda que haja quem sinta prazer com tais coisas.

Mesmo sendo bons por natureza, tais prazeres devem ser buscados moderadamente ${ }^{39}$. Ora, o temperante é justamente aquele que busca prazeres sadios na justa medida e no momento oportuno; nem mais, nem menos do que é preciso. O critério, portanto, para que um prazer seja bom é que ele seja conforme a natureza e que seja desejado moderadamente. Porém, para que não vigore um universalismo quanto aos bons prazeres, é preciso que tais prazeres naturais sejam considerados relativamente a cada um, pois são mais ou menos apropriados segundo as circunstâncias particulares. De fato, a ética aristotélica é antes particularista do que universalista, como bem sabemos e como também afirmou Alexandre de Afrodisia ${ }^{40}$. Não seria adequado, nem deveras possível estabelecer uma categoria que liste os prazeres bons e os ruins, mas seria possível mostrar qual é a propriedade que nos permite generalizar e discernir o bom do mau prazer. Eis a propriedade geral: nenhum prazer natural é excessivo, portanto não envolve dor. Ao contrário: todo prazer antinatural envolve dor por ser excessivo e tudo o que é excessivo é contrário à reta razão, i.e., àquilo que nos é mais específico e divino de nossa natureza.

Em concordância com a interpretação de Alexandre, podemos constatar que o estagirita, em ENVII 14, estabelece clara distinção entre prazer natural (physeihêdea) e o que poderíamos chamar de prazer "antinatural" ${ }^{41}$. O prazer natural não envolve dor, pois não admite excesso ${ }^{42}, \mathrm{o}$ que é evidente no caso da ação virtuosa. A ação virtuosa é prazerosa por natureza, portanto, não envolve dor psíquica; embora possa envolver dor física, como é tipicamente o caso da ação corajosa. Já o prazer antinatural ou contrário à natureza envolve dor. A dor aqui referida é o sofrimento causado pela sua ausência, pois não ter prazer é doloroso para quem o busca excessivamente ${ }^{43}$.

Também em ENVII 4, temos a distinção entre prazer por natureza ( $p h y$ seihaireta), contrário à natureza (enantia) e intermediário ou neutro (meta$z u)^{44}$. Aqueles que são desejados por natureza, e não de modo excessivo, são belos e bons, como "a vitória, a honra, a riqueza e outras coisas prazerosas do mesmo tipo" (1147b30). Os neutros são os prazeres necessários corporais que, em si mesmos, não são nem bons nem ruins, mas, se desejados excessivamente, tornam-se ruins; se moderadamente, tornam-se bons. Já os 
contrários à natureza são todos aqueles cuja fonte é ruim e/ou o modo de desejar é excessivo, portanto, são contrários à razão (para ton logon) ${ }^{45}$.

Como vemos, Aristóteles concebe dois critérios para se determinar o valor moral de um prazer: um critério objetivo e o outro, por assim dizer, subjetivo. Dizemos que o critério objetivo é o valor moral de sua fonte, i.e., da atividade à qual pertence, independentemente do modo como o sujeito frui este prazer. Se ela for contrária à natureza, o prazer será antinatural e excessivo, portanto moralmente ruim. Se ela for conforme a natureza, o prazer será natural e poderá ser bom se for desejado e fruído moderadamente. O critério pelo modo, excessivo ou moderado, de se desejar e fruir o prazer pode ser entendido como subjetivo, em distinção daquele outro, o objetivo. Temos, por um lado, o objeto de prazer, i.e., a atividade prazerosa, que determina objetivamente o valor moral do prazer, e, por outro, o modo de fruir este prazer, que determina subjetivamente o valor moral do prazer. Se o modo for excessivo, o resultado são prazeres ruins, mesmo que as atividades sejam, elas próprias, boas. Se o modo for moderado, o resultado é um bom prazer e isto apenas com relação às boas atividades, pois às ruins sempre se seguirão maus prazeres, independentemente do modo de se desejar. Por exemplo, o estupro é uma atividade prazerosa para aquele que a exerce e em si mesma ruim, independentemente do modo de exercê-la, se excessivo ou moderado. Ou seja, não há como dizer que estuprar moderadamente seria bom. Neste caso, quando a atividade é ela própria ruim, o critério subjetivo fica excluído. Agora, quando a atividade é boa, por exemplo quanto ao beber vinho, o modo de bebê-lo, se moderado ou excessivo, deve ser aplicado.

Disto concluímos que o critério subjetivo vale apenas para os prazeres que já cumpriram o critério objetivo, ou seja, cuja fonte é conforme a natureza. Que os bons prazeres ou os neutros se tornam prejudiciais quando desejados de modo excessivo é evidente, afinal, “os homens não são censurados por experimentá-los, desejá-los ou amá-los, mas pelo modo, i.e., por

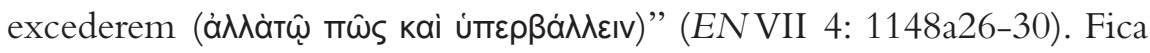
demonstrado, pelo que foi dito, que o erro moral concernente aos prazeres consiste no excesso, no contrário ao natural, ao racional, seja quanto ao objeto: à atividade prazerosa, seja quanto ao modo de se desejar esta atividade.

Parece ser também evidente, conforme o que dissemos, que aquele que age em vista do prazer e não em conformidade com a reta razão, age 
antes conforme a natureza animal do que a humana. Ora, é nítida a distinção da superioridade que Aristóteles atribui à natureza humana naquilo que justamente a diferencia da dos animais: a razão. Logo, seria baixo e vil agir conforme os apetites e contrariamente à razão, como fazem os controlados (akratês) e intemperantes (akolastos). Em suma, agir como um animal é agir contra a natureza humana, contra a razão, é tornar-se vicioso; ainda pior, é encaminhar-se para o limite do campo moral, campo este que define a própria essência do homem. Se a bestialidade e a divindade são os limites da humanidade ${ }^{46}$, então, o vicioso está mais próximo da bestialidade, ao perseguir prazeres excessivos, e o virtuoso, da divindade, ao exercer bem o que há em nós de divino: a razão.

\section{Conclusão}

Podemos concluir que, como o virtuoso não age devido ao prazer, mas certamente com prazer, o prazer em absoluto jamais poderia ser o fim da ação virtuosa, mas sim a boa ação acompanhada de prazer natural e moderado. Com efeito, não é possível desejar o prazer simplesmente, pois que o prazer, ele mesmo, não existe em separado da atividade. Podemos desejar algo e este algo nos aparecer como sendo prazeroso, mas não podemos desejar $o$ prazer. O prazer não existe como uma substância em separado, i.e., ele não subsiste por si mesmo. Ele é sempre um atributo que qualifica uma substância (i.e., uma atividade) como prazerosa. Ele mesmo não existe senão como uma qualidade que pertence a uma atividade quando esta nos parece ser prazerosa.

Assim, não apenas é impossível, do ponto de vista ontológico, desejar o prazer independentemente da atividade ao qual ele pertence, como também é impróprio, do ponto de vista ético, desejar uma atividade por ela ser prazerosa em preferência de ela ser boa. Como vimos, segundo o estagirita, nós devemos desejar a ação virtuosa por ela mesma e não pelo prazer que lhe acompanha.Vimos também que o virtuoso deseja realizar a boa atividade e nunca o prazer acima dela. Neste sentido, desejar ter prazer não é senão desejar realizar certa atividade. Do mesmo modo, desejar ter bons prazeres não é senão desejar realizar boas atividades.

Esta concepção aristotélica de prazer parece não admitir que o bom julgamento dependa do que nos aparece como sendo prazeroso. Ao 
contrário, o que nos aparece como sendo prazeroso deve depender do bom julgamento, e assim ocorre no caso do virtuoso. Assim, tudo o que Aristóteles parece querer evitar é que nós tomemos o prazer e a dor como fundamentos do valor moral da ação. É possível, e, mais do que isso, é eticamente necessário que o bem seja feito não porque agir bem nos dá prazer, mas porque é o que é preciso ser feito, mesmo que não nos desse prazer ${ }^{47}$.

Como, no caso do virtuoso, é inevitável sentir prazer ao fazer o bem, certamente é preciso deixar claro que ele faz o bem com prazer e não devido ao prazer. Ele faz o bem devido ao próprio bem e por isso sente prazer. Fica patente que, em se tratando de uma pessoa virtuosa, o prazer é a consequência inevitável da ação virtuosa e não a sua razão. É possível e absolutamente imprescindível do ponto de vista ético agir bem sem ser movido pelo prazer, pois, do contrário, agiríamos sempre por causa de uma espécie de um prazer 'egoísta'. Mas o virtuoso age virtuosamente por querer agir assim, e, ao mesmo tempo, acaba por sentir em mais alto grau o bom prazer, o prazer do virtuoso. Dorothea Frede expressou com agudeza o cerne inovador da concepção aristotélica de prazer:

"Ela libera as ações moralmente boas de sua suspeita de esconder um egoísmo hedonista. Se ajudo alguém, segundo a explicação de Aristóteles, não o faço para obter, para mim, prazer pelo fato de estar ajudando, mas sim porque é a ação correta naquelas circunstâncias. E é por isso que ela me causa prazer" (FREDE, 2006, p. 241).

Podemos, portanto, concluir que a definição do prazer como um fenômeno cuja existência e natureza dependem inteiramente da atividade a qual pertence nos permite inferir que o juízo de valor que incide sobre a atividade é o critério de valoração moral do prazer, e não o contrário. Com efeito, é preciso que o bem em si mesmo seja também bom para aquele que ama o bem; assim como é preciso que o que é prazeroso em si mesmo seja prazeroso para o virtuoso, o que significa dizer que o virtuoso sabe desejar e sentir prazer conforme a reta razão. A operação desiderativa ideal é justamente aquela do homem bom, ou seja, aquela daquele que já habituou o seu desejo a ser conforme a reta razão, que aprendeu a desejar conforme o bom julgamento. Tornar-se virtuoso é passar a desejar e a sentir prazer com o que é bom por ser realmente bom, ao contrário do vicioso, que não faz senão desejar simplesmente o que lhe aparece como 
prazeroso. Eis a fórmula aristotélica que expressa a profunda e necessária relação entre prazer e virtude: o virtuoso apreende e deseja corretamente o que é bom e o que é bom necessariamente lhe aparece como prazeroso.

${ }^{1} \mathrm{O}$ mesmo é dito mais adiante, em 1105b21-3.

${ }^{2}$ Linhas adiante, a mesma tese será dita da seguinte maneira: "aquele que se comporta bem com relação aos prazeres e dores será bom, quem se comporta mal, será mau” (1105a13-4).





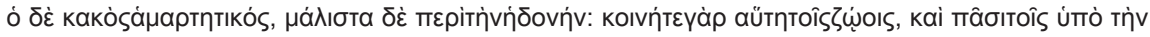

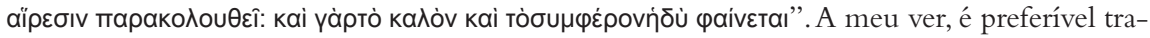
duzir aipeøıv por objeto de busca, embora seja comumente traduzido por objeto de escolha, pois os animais não escolhem, mas buscam algo na medida em que o desejam. Portanto, aïpદбıv, neste sentido, é o mesmo que perseguir, buscar ou mesmo desejar um objeto que esteja em nosso poder realizar e não uma operação racional de eleição de um objeto antes que outros. Se optarmos pelo termo escolha para traduzi-lo, então temos que ter em mente que se trata de uma simples escolha, tão simples que poderia ser atribuída aos animais, e não poderia se tratar da escolha deliberada. Como razão suplementar para justificar esta tradução, cito Zingano: "A expressão para objetos de busca é ta eis tashaireseis e a tentação é grande de traduzir por objetos de escolha, mas a noção de hairesis está frequentemente associada e mesmo assimilada a diokton, tipicamente objeto de busca (cf. I 5 1097a30-34; VII 10 1151b1), o que sugere fortemente a tratá-la como um sinônimo desta. A vantagem é também conceitual, pois, como Aristóteles insiste, toda escolha diz respeito a um meio, enquanto o objeto de busca é um fim a partir do qual deliberamos sobre os meios" (ZINGANO, M., 2008, nota 1104b30-31). Deixo registrado aqui que me utilizarei de sua tradução, com possíveis modificações, para todas as outras passagens referentes ao Tratado da Virtude Moral: EN I 13 - III 8: 1102a5 - 1115a3. As outras passagens são minhas traduções.

${ }^{4}$ Evidentemente, buscar algo é distinto de simplesmente desejar algo, pois posso desejar e não buscar, como o desejo por coisas impossíveis, por exemplo, o desejo pela imortalidade. Porém, no que diz respeito a coisas possíveis, i.e., que estão em nosso poder realizar, desejar e buscar coincidem.

${ }^{5}$ Como o próprio estagirita nos diz: "nós regulamos (kanonizomen) as ações, uns mais, outros menos, pelo prazer e pela dor" (1105a4-5).

${ }^{6}$ Cf. EN I, 8, 1098b9-1099b8.

${ }^{7}$ Cf. EN I, 5, 1095b15-18.

${ }^{8}$ Cf. ENVII, 11, $1152 \mathrm{~b} 6$.

${ }^{9}$ Cf. EN I, 5, 1095b15-18.

${ }^{10}$ O primeiro tratado compreende os capítulos 12 ao15 do sétimo livro da Ética Nicomaqueia, e o segundo tratado, os capítulos 1 ao5 do décimo livro da referida obra. Resumidamente, 
podemos dizer que, nos dois tratados, o filósofo se opõe à opinião radicalmente anti-hedonista, atribuída a Espeusipo, de que o prazer é o mal, bem como à opinião estritamente hedonista, atribuída a Eudoxo, de que o prazer é o bem.

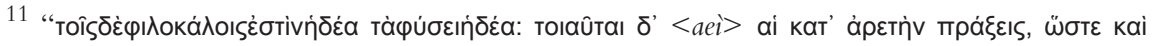

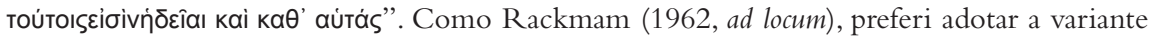
aei, o que favorece a tese de que as ações em si mesmas ou por natureza prazerosas são sempre virtuosas.

12 Cf. ENVIII 2: 1155b21-3.

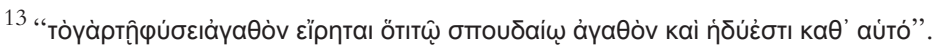

${ }^{14}$ Esta tese do virtuoso como aquele que não institui o bem na realidade, mas que o apreende corretamente, i.e., que toma como um bem para si o que é bom em si ou por natureza, também é evidente neste outro trecho: "o homem virtuoso julga corretamente cada coisa e em cada uma a verdade se manifesta a ele, pois há coisas belas e prazerosas próprias a cada disposição e presumivelmente o homem virtuoso se distingue sobretudo pelo fato de ver o verdadeiro em cada coisa, como se fosse um padrão e uma medida delas" (EN III 4: 1113a31-4).

${ }^{15}$ Sobre os exemplos de coragem por homonímia, ver EN III 8: $1116 a 15$ e ss.

${ }^{16}$ Ver também EN III 8: 1115b23-24.

${ }^{17}$ A ideia de que o prazer é propriamente uma sensação da alma está presente não apenas no trecho citado de EN I 8, mas também em III 10, pois, em algumas atividades, como na ambição (philotimia) e no amor ao aprendizado (philomatheia), sentimos prazer menos com o corpo sendo afetado e mais com a mente (allamallontesdianoias). Ou seja, o corpo sofre algo, pois há percepção, imaginação e alterações físicas, mas a sensação de prazer parece ser predominantemente uma atividade da alma.

${ }^{18}$ A tese de que o prazer é um sinal do tipo de disposição será exposta pelo filósofo em EN II 3: 1104b4. Ver também EN X 5: 1176a27-29. Alexandre de Afrodisia afirma que o prazer é um sinal de que a virtude e a felicidade estão presentes no homem virtuoso: “(...) o prazer, acompanhando a atividade que surge desse modo [desimpedido], será um sinal de que a felicidade está presente para aqueles que agem deste modo (i.e., virtuosamente), antes de ser [ele mesmo] a felicidade" (Problema 13: 143, 28-30).

${ }^{19}$ Cf. EN II 3: 1105a4.

${ }^{20}$ Não cabe analisarmos em detalhe o prazer que sente o controlado ou o descontrolado, mas, brevemente, podemos dizer que ambos parecem não desejar o bem por ele mesmo, como ocorre com o virtuoso, mas a consequência prazerosa ou não penosa de realizá-lo, i.e., a consequência de ser elogiado ou de não ser punido por fazer o que é bom em detrimento ao que conduz o apetite excessivo.

${ }^{21}$ O tipo de prazer será determinado pelo tipo de atividade, se boa, um bom prazer, se má, um mau prazer, como veremos adiante no texto, item III. A definição de prazer.

22 O mesmo diz Tomás de Aquino ao interpretar EN II 3 (1993, lição XI, \$1470): “Com relação ao prazer, uma coisa é denominada má, e outra, da mesma forma, boa. Um homem bom

doispontos, Curitiba, São Carlos, vol. 10, n. 2, p.315-342, outubro, 2013 
é tido como aquele que tem prazer por coisas boas. Um homem mau, aquele que se deleita por coisas más".

${ }^{23}$ Cf. EN II, 2: 1104b8-13.

${ }^{24}$ Ou seja, para saber o que dá prazer, basta discriminar sensivelmente o objeto prazeroso. Não faz sentido ao intemperante avaliar moralmente o prazer que ele busca, pois ele faz um uso meramente instrumental da razão, i.e., ele apreende os meios mais eficazes para realizar o seu prazer. Em EN III 11: 1119a19-21, Aristóteles nos diz que o intemperante é aquele que tem mais em conta os prazeres que persegue do que o que é digno (axias).

${ }^{25}$ Ao comparar ter prazer com ver ou ter qualquer outra sensação, Aristóteles iguala a sensação de prazer a uma atividade tal qual a perceptiva, distinguindo-o do movimento. Como ele diz: "não é possível se mover senão ao longo do tempo, mas é possível sentir prazer (hêdesthai), pois aquilo que existe em um instante é um todo completo (to garentoinunholon ti)" (EN X, $4,1174 \mathrm{~b} 9)$.

${ }^{26}$ Cf. EN X, 4, $1174 \mathrm{~b} 33$.

${ }^{27}$ Cf. EN X, 5, 1175a27-b1.

${ }^{28}$ Cf. EN X, 5, 1175b21-22.

${ }^{29}$ De todo modo, o estagirita nos diz que, mesmo sendo estreitamente unidos, seria absurdo confundir o prazer com a atividade à qual ele pertence (EN X, 5, 1175b30-34).

${ }^{30}$ Cf. EN III 12: 1119a12-21.

31 Sobre o spoudaios ser como uma medida, um metron, ver também EN IX 4: 1166a13.

32 Sobre a razão estar corrompida no caso do intemperante, ver EN III 12: 1119b8-12.

${ }^{33}$ Cf. Met. IX, 2, 1046a36-b28.

${ }^{34}$ Depois de dizer que o movimento implica três coisas: aquilo que move, aquilo que move e é movido, e aquilo que é movido, Aristóteles define o desejo da seguinte maneira:"Aquilo que move sem ser movido é o bem prático, aquilo que move e é movido é a faculdade desiderativa (to orektikon) (pois aquilo que é movido assim o é na medida em que deseja, e o desejo (orexis) é um movimento (kinesis) ou atividade (energeia)), e aquilo que é movido é o animal" (DA III, 10, 433b15-18). O termo desejo refere-se aorexis, gênero de três espécies de desejo: querer (boulêsis), ter apetite (epithumia) e ter impulso (thumos).

35 Cf. EN I 13 eVI 2, 1139a27.

${ }^{36}$ Como diz Aristóteles: "que nós temos que agir de acordo com a reta razão (kata ton orthon logon) é um princípio comum e deve ser assumido" (EN II 2: 1103b33-34). No livro VI, é provável que o filósofo venha a corrigir esta tese ao estabelecer que nós devemos agir não kata logon, mas meta logou. Isso porque, nas palavras do mesmo, "a virtude não é meramente uma disposição conforme a reta razão (kata ton orthon logon), mas uma disposição com reta razão (meta touorthoûlogou)" (ENVI 13: 1144b26-27). Sobre este assunto, ver Zingano, M. Agir secundumrationem ou cum ratione. In: ZINGANO (2007).

${ }^{37}$ Classificação, como veremos adiante, exposta em ENVII 4. 
38 Como já fora explicado no item II. O hedonismo moderado de Aristóteles deste artigo, do mesmo modo em que há bem em si e bem para mim, há prazer em si e prazer para mim. Cf. ENVIII, 2, 1155b21-3.

39 Sabemos que, segundo a ética aristotélica, a virtude é uma disposição para agir moderadamente, ou melhor, na justa medida com relação às emoções. Nas palavras do filósofo: "por disposições <entendemos> aqueles estados em função dos quais nos portamos (echomen) bem ou mal com relação às emoções: por exemplo, com relação ao encolerizar-se, se nos encolerizarmos forte ou fracamente, portamo-nos mal; se moderadamente (mesôs), bem, e de modo semelhante com relação às outras emoções" (EN II 4: 1105b26-29). Assim, a moderação com relação aos desejos e emoções é atributo essencial para ação e disposição virtuosas.

${ }^{40}$ Cf. Alexandre de Afrodisia, Problema 5, 125, 24-28.

${ }^{41}$ Além do prazer excessivo, próprio da disposição intemperante ou acrática, o prazer bestial também é considerado antinatural; porém, o primeiro encontra-se no campo moral, enquanto o segundo o extrapola. Sobre o prazer bestial, ver ENVII, 5, 1148b15-20.

${ }^{42}$ Cf. ENVII, 14, 1154b15.

43 Cf. ENVII, 14, 1154a20-21.

${ }^{44}$ Cf. ENVII, 4, 1148a22-b5.

${ }^{45}$ Cf. ENVII, 4, 1148a29.

${ }^{46}$ Inferência feita a partir, sobretudo, de ENVII 1.

${ }^{47}$ Cf. EN X, 3, 1174a6-8.

\section{Referências bibliográficas}

ARISTÓTELES. 1831-1870. Opera ex recensione I. Bekker. Berlin: Academia Regia Borussica.

. De Anima. 1990. Trad., introd. e notas de R. D. Hicks. New York: Georg OlmsVerlag.

. De l'Ame. 1993. Trad. de R. Bodéüs. Paris: Flammarion. . Aristotle De Anima. 1961. Trad. de W. Ross. Oxford: Oxford University Press.

. On the Soul, Parva Naturalia, On Breath. 1936. Trad. de W. Hett. Cambridge: Havard University Press. 1980. Works of Aristotle. In: ROSS, W. D. The Great Books. Oxford: University Press. 
. Ética a Nicómaco. 2002. Trad. Araujo, M. e Marías, J. Madrid:

Centro de Estudios Políticos y Constitucionales.

. Nichomachean Ethics. 1999. Trad. de Terence Irwin. Ed. Indianapolis. . The Nichomachean Ethics. 1962. Trad. de Rackham. Havard: Loeb Classical Library.

. Aristotle: Nichomachean Ethics. 2002. Trad. de Christopher Rowe. Oxford.

ALEXANDRE OF APHRODISIAS. 1990. Ethical Problems. Trad. de Sharples. New York: Cornell University Press.

ANNA, J. 1980. Aristotle on Pleasure and Goodness. In: RORTY, A. O. Essays on Aristotle's Ethics. California: University of California Press.

AQUINO, T. 1993. Commentary on Aristotle's Nicomachean Ethics. Notre Dame: Dumb Ox Books.

AUBRY, G. 2005. Nicomachean Ethics VII 14, (1154a22-b34): The Pain of the Living and Divine Pleasure. In: NATALI, C. (ed) Aristotle: Nicomachean Ethics, Book VII - Symposium Aristotelicum.. Oxford: Oxford University Press, pp. 237-263.

BARNES, SCHOFIELD \& SORABJI. 1977. Articles on Aristotle: Ethics and Politics. London: Duckworth. 1979. Articles on Aristotle 4: Psychology and Aesthetics. London:

Duckworth.

BARNES, J. 1995. The Cambridge Companion to Aristotle. Cambridge: University Press.

FESTUGIÈRE, A. J. 1946. Aristotle: Le plaisir. Paris.

FREDE, D. 2005. Nicomachean Ethics VII 11-12: Pleasure. In: NATALI, C. (ed).. Aristotle: Nicomachean Ethics, Book VII - Symposium Aristotelicum. Oxford: Oxford University Press, pp. 183-207. 2009. Prazer e dor na ética aristotélica. In: KRAUT, R. Aristóteles: A Ética a Nicômaco. Porto Alegre: Artmed, pp. 236-253. 
GOSLING \& TAYLOR. 1982. The Greeks on Pleasure. Oxford: Clarendon Press.

OWEN, G.E.L. 1977. Aristotelian Pleasures. In: BARNES, SCHOFIELD \& SORABJI. Articles on Aristotle: Ethics and Politics. London: Duckworth.

RAPP, C. 2005. Nicomachean Ethics VII 13-14 (1154a21): Pleasure and eudaimonia. In: NATALI, C. (ed). Aristotle: Nicomachean Ethics, Book VII - Symposium Aristotelicum. Oxford: Oxford University Press, pp. 209-235. RIEL, G.V. 2000. Pleasure and Good Life: Plato, Aristotle and the Neoplatonists. Boston: Brill.

RORTY,A. O. 1980. Essays on Aristotle's Ethics. California: University of California Press. 1980. Akrasia and Pleasure: Nicomachean Ethics Book 7.

In: RORTY, A. O. Essays on Aristotle's Ethics. California: University of California Press. 1974. The Place of Pleasure in Aristotle's Ethics. Mind 83, pp. 481-497.

ROSS, D. 1961. De Anima: edited with introduction and commentary. Oxford: Clarenton Press.

ZINGANO, M. 2007. Estudos de Ética Antiga. Col. Philosofia. Porto Alegre: Discurso Editorial. 2008. Ethicanicomachea I 13 - III 8:Tratado da Virtude Moral. Trad. de Marco Zingano. São Paulo: Odysseus. (org.) 2010. Sobre a Ética Nicomaqueia de Aristóteles. São Paulo: Odysseus. 